\title{
Serial blood eosinophils and clinical outcome in patients with chronic obstructive pulmonary disease
}

Sun Hye Shin ${ }^{1}$, Hye Yun Park ${ }^{1 *}$ D, Danbee Kang ${ }^{2}$, Juhee Cho ${ }^{2,3,4}$, Sung Ok Kwon ${ }^{5}$, Joo Hun Park ${ }^{6}$, Jae Seung Lee, Yeon-Mok Oh${ }^{7}$, Don D. Sin ${ }^{8}$, Woo Jin Kim" ${ }^{9^{*}}$, Sang-Do Lee ${ }^{7}$ and KOLD Study Group

\begin{abstract}
Background: Blood eosinophils have been suggested as a potential biomarker in chronic obstructive pulmonary disease (COPD), and their stability over time has been investigated in a few studies. However, the association between the stability of blood eosinophils and long-term clinical outcomes in COPD patients has yet to be fully elucidated. This study aimed to evaluate the stability of blood eosinophils and its association with clinical outcomes in COPD patients.

Methods: In total, 299 COPD patients from the Korean Obstructive Lung Disease cohort with at least two blood eosinophil measurements were included. Patients were stratified according to a cut-off of $300 \mathrm{cells} / \mu \mathrm{L}$, and the association between eosinophil changes and all-cause mortality was analysed. The annual decline in forced expiratory volume in $1 \mathrm{~s}\left(\mathrm{FEV}_{1}\right)$, serial changes in St George's Respiratory Questionnaire score (SGRQ), and exacerbations during follow-up were compared among eosinophil groups.

Results: Patients were stratified into three groups according to the blood eosinophil cut-off: persistently $<300$ cells $/ \mu \mathrm{L}(\mathrm{PL} ; n=175)$, variable $(\mathrm{V} ; n=68)$, and persistently $\geq 300$ cells $/ \mu \mathrm{L}(\mathrm{PH} ; n=56)$. There were no significant differences in baseline characteristics (age, sex, smoking, body mass index, use of inhaled corticosteroids, exacerbations in the previous year, $\mathrm{FEV}_{1}$ ( $\mathrm{L}$ or \% predicted), or emphysema score) among the groups. During a median follow-up of 6.0 years, the $\mathrm{PH}$ group had a better survival rate than the PL group (adjusted mortality rate ratio, $0.29 ; 95 \%$ confidence interval, $0.09-0.97 ; P=0.045$ ). The $\mathrm{PH}$ group also showed improved symptoms and impact domains of SGRQ score compared to the PL group. No difference was found in annual $\mathrm{FEV}_{1}$ decline or exacerbations during follow-up among the groups.
\end{abstract}

Conclusions: Patients with persistently high blood eosinophils had a better survival rate than those with persistently low blood eosinophils. Serial follow-up of blood eosinophils could help to predict outcomes in COPD patients.

Keywords: Chronic obstructive pulmonary disease, Eosinophil, Stability, Lung function

\footnotetext{
* Correspondence: hyeyunpark@skku.edu; pulmo2@kangwon.ac.kr tHye Yun Park and Woo Jin Kim contributed equally to this work. ${ }^{1}$ Division of Pulmonary and Critical Care Medicine, Department of Medicine, Samsung Medical Center, Sungkyunkwan University School of Medicine, 81 Irwon-ro, Gangnam-gu, Seoul 06351, South Korea

${ }^{9}$ Department of Internal Medicine and Environmental Health Center, Kangwon National University Hospital, School of Medicine, Kangwon National University, 156 Baengyeong-ro, Chuncheon-si, Gangwon-do 200-722, South Korea

Full list of author information is available at the end of the article
}

(C) The Author(s). 2018 Open Access This article is distributed under the terms of the Creative Commons Attribution 4.0 International License (http://creativecommons.org/licenses/by/4.0/), which permits unrestricted use, distribution, and reproduction in any medium, provided you give appropriate credit to the original author(s) and the source, provide a link to the Creative Commons license, and indicate if changes were made. The Creative Commons Public Domain Dedication waiver (http://creativecommons.org/publicdomain/zero/1.0/) applies to the data made available in this article, unless otherwise stated. 


\section{Background}

Neutrophilic inflammation profiles are generally recognised in chronic obstructive pulmonary disease (COPD) [1] but eosinophilic inflammation in sputum has also been investigated as a predictor of the corticosteroid response [2, 3]. Recently, awareness of the role played by peripheral blood eosinophils in COPD has increased, with reports showing that the peripheral blood eosinophil count corresponds to eosinophilic inflammation in the airway [4-6]. Although there is no consensus regarding the most appropriate cut-off value, higher blood eosinophils are linked to an improved response to inhaled corticosteroids (ICS) in preventing lung function decline [7] and exacerbations in COPD patients [8-12]. Together alongside concerns regarding the pneumonia risk associated with ICS [13] and the efficacy of dual bronchodilator therapy [14, 15], the Global Initiative for Chronic Obstructive Lung Disease suggests the use of ICS in frequent exacerbators with high blood eosinophils. [16] However, clinical outcomes related to increased blood eosinophils show heterogeneous features: increased risk of acute exacerbations (AE) [17] and readmission [18], but with fewer symptoms [19], better baseline lung function [19] with slower decline [20], fewer comorbidities [21] and an even lower mortality rate $[22,23]$.

As a biomarker in COPD, a single blood eosinophil measurement might not indicate a stable condition. ECLIPSE (Evaluation of COPD Longitudinally to Identify Predictive Surrogate End-points) investigators found that only $51 \%$ of subjects had a stable eosinophil count of below or above $2 \%$ over a 3 -year period [19]. Another prospective observational study that measured blood eosinophils every 3 months over a 1 -year period revealed that $65 \%$ of COPD patients remained persistently above or below a level of 400 cells $/ \mu \mathrm{L}$ [24]. Recently published data from the general population showed that the long-term stability of blood eosinophils using a cut-off of 340 cells $/ \mu \mathrm{L}$ was $75 \%$ across 1 year, $49 \%$ across 4 years, and 35\% across 8 years [25]. That study also found significantly lower stability in patients with a baseline blood eosinophil count greater than 340 cells $/ \mu \mathrm{L}$. Therefore, despite variable cut-off values, the results of previous studies suggest that a considerable proportion of patients will have oscillating blood eosinophil levels over time. Nevertheless, a lack of data precludes comparisons between clinical outcomes and the stability of blood eosinophils over time. Therefore, we evaluated blood eosinophil stability across two measurements and sought associations with long-term clinical outcomes, such as lung function decline and mortality, in COPD patients using data from an observational cohort study.

\section{Methods}

\section{Study population}

The study participants included 466 COPD patients from the Korean Obstructive Lung Disease (KOLD) cohort. Details of the KOLD study protocol were published previously [26]. Recruitment took place in pulmonary clinics across 16 hospitals in the Republic of Korea from June 2005 to June 2015. The inclusion criteria were: 1) 40 years of age or older; 2) COPD, defined as a post-bronchodilator forced expiratory volume in $1 \mathrm{~s}$ $\left(\mathrm{FEV}_{1}\right) /$ forced vital capacity $(\mathrm{FVC})$ ratio $<0.7$ and a smoking history of more than 10 pack-years; and 3) no history or radiographic evidence of tuberculosis, bronchiectasis, or other pulmonary disorders. Participation was further restricted to those with baseline and serial peripheral blood eosinophil counts; one patient with only a baseline spirometry measurement was excluded. The final sample included 299 patients. The study protocol was approved by the Institutional Review Board of Asan Medical Center (no. 2005-0010). Written informed consent was obtained from all participants.

\section{Blood eosinophils}

Using whole blood samples collected from patients, complete blood cell counts were conducted using an automated hematology analyser at each participating hospital. Samples were taken at baseline and every year, where possible, as per the protocol. Two serial measurements, baseline and at 1 year $(n=278)$, baseline and at 2 years due to the absence of 1 -year measurement $(n=13)$, or baseline and at 3 years due to an absence of 1 - and 2-year measurements $(n=8)$ were used in this analysis. The percentage of eosinophils was multiplied by the white blood cell count to give the absolute eosinophil count. A pre-specified eosinophil cut-off of 300 cells $/ \mu \mathrm{L}$ was used to characterise the study cohort and determine associations with clinical outcomes $[10,20,27]$. Using this cut-off, the subjects were stratified into three groups according to the serial eosinophil count: persistently $<300$ cell $/ \mu \mathrm{L}$ (persistently low; PL), variable above and below 300 cell $/ \mu \mathrm{L}$ (variable; V), and persistently $\geq 300 \mathrm{cell} / \mu \mathrm{L}$ (persistently high; $\mathrm{PH}$ ).

\section{Outcome measurements}

The primary endpoint was the mortality rate at 8 years. Participants were followed from their baseline visit to death or the last available visit.

As per the study protocol, spirometry was performed every 3 months where possible. The mean (standard deviation, $\mathrm{SD}$ ) number of spirometry tests per subjects was 9.1 (4.6) and the mean (SD) interval between each spirometry test was $0.56(0.36)$ years. Spirometry was performed according to the recommendations of the 
American Thoracic Society/European Respiratory Society using Vmax 22 (Sensor-Medics, Yorba Linda, CA, USA) and PFDX equipment (MedGraphics, St Paul, $\mathrm{MN}, \mathrm{USA}$ ) [28]. Absolute FVC and $\mathrm{FEV}_{1}$ values were acquired, and the percentage of their predicted values was calculated from equations obtained using a representative Korean sample [29]. Reversibility was defined as a post-bronchodilator increase in $\mathrm{FEV}_{1}$ of at least $12 \%$ and $200 \mathrm{~mL}$ from the baseline value [16].

St George's Respiratory Questionnaire (SGRQ) [30] scores were obtained every year during follow-up [26]. AEs were assessed at the clinic every 3 months, where possible. Moderate AE was defined as a clinic visit, while severe AE was defined as hospitalization or an emergency room visit owing to one or more of the following: worsening of dyspnea, increased sputum volume and purulent sputum [31].

\section{Statistical analyses}

Incidence rates for overall mortality were calculated by dividing the number of deaths during the study period by the total observation time. A Poisson regression model was used to estimate the mortality rate ratio (MRR) of the $\mathrm{V}$ and $\mathrm{PH}$ groups compared to the PL group. Univariable and multivariable analyses were conducted to investigate the association between eosinophil changes and mortality. Multivariable analysis variables included age, smoking status, self-reported history of asthma, two or more moderate exacerbations or one or more severe exacerbations during the previous year, a post-bronchodilator $\mathrm{FEV}_{1}<50 \%$ predicted at baseline, and use of ICS/long-acting $\beta_{2}$-agonist (LABA) or ICS for more than two thirds of the study period.

Serial changes in $\mathrm{FEV}_{1}$ or the SGRQ score were also compared among the groups using linear mixed models for longitudinal data with random intercepts and random slopes [32]. Models were adjusted to account for potential confounding factors: age, smoking status, self-reported history of asthma, two or more moderate exacerbations or one or more severe exacerbations during the previous year, and use of ICS/LABA or ICS for more than two thirds of the study period. Regarding serial changes in the SGRQ score, a post-bronchodilator $\mathrm{FEV}_{1}<50 \%$ predicted at baseline was further adjusted.

All tests were two-sided, and $p$-values $<0.05$ were considered significant. All analyses were performed using Stata software (ver. 14.0; Stata Corporation, College Station, TX, USA).

\section{Results}

The mean (SD) age of the study participants was 66.8 (7.4) years, and the mean duration between eosinophil measurements was 13.3 (4.8) months. Among the 299 COPD subjects, 175 (58.5\%), 68 (22.7\%), and 56 (18.7\%) subjects were stratified into the PL, V, and $\mathrm{PH}$ groups, respectively (Fig. 1). The mean (SD) blood eosinophil count at baseline was 143.4 (73.4) cells $/ \mu \mathrm{L}, 339.0$ (191.6) cells $/ \mu \mathrm{L}$, and 681.0 (595.6) cells $/ \mu \mathrm{L}$ in the PL, V, and PH groups, respectively. Compared to the $\mathrm{PH}$ group, the rate of use of a long-acting muscarinic antagonist was significantly higher in the PL group, but there were no significant differences in terms of age, sex, smoking history, body mass index (BMI), education, symptoms and two or more moderate exacerbations or one or more severe exacerbations during the previous year, self-reported history of asthma, presence of emphysema, or use of ICS/LABA or ICS at baseline (Table 1). The use of ICS or systemic corticosteroids did not differ among groups during the follow-up (Additional file 1: Table S1).

The median follow-up duration was 6.0 years (interquartile range: 3.7-8.0 years), contributing 1649 person-years of follow-up. During follow-up, 28, 5, and 2 subjects in the PL, V, and PH groups died, respectively. The overall mortality rate was significantly lower in the $\mathrm{PH}$ group (0.6 [95\% confidence interval (CI), 0.2-2.4] per 100 person-years) compared to the PL group $(3.0[95 \% \mathrm{CI}, 2.1-4.3]$ per 100 person-years) (MRR, 0.27; 95\% CI 0.08-0.87; $P=$ 0.029; Table 2). The $\mathrm{V}$ group had a lower mortality rate than the $\mathrm{PL}$ group, but the difference was not significant (MRR, 0.68; 95\% CI, 0.32-1.43; $P=0.31$ ). After adjusting for age, smoking status, self-reported history of asthma, two or more moderate exacerbations or one or more severe exacerbations during the previous year, post-bronchodilator $\mathrm{FEV}_{1}<50 \%$ predicted at baseline, and use of ICS/LABA or ICS for more than two thirds of the study period, the $\mathrm{PH}$ group still had a significantly lower mortality rate than the PL group (MRR, 0.29; 95\% CI, 0.09-0.97, $P=0.045$ ) (Fig. 2).

Among all participants, the annual change in $\mathrm{FEV}_{1}$ was $-29.71 \mathrm{~mL}$ in the PL group, $-18.48 \mathrm{~mL}$ in the $\mathrm{V}$ group, and $-28.15 \mathrm{~mL}$ in the $\mathrm{PH}$ group. Although the annual change in $\mathrm{FEV}_{1}$ was modest in the $\mathrm{V}$ and $\mathrm{PH}$ groups compared to the PL group, the differences were not significant even after adjusting for age, smoking status, self-reported history of asthma, two or more moderate exacerbations or one or more severe exacerbations during the previous year, and use of ICS/LABA or ICS for more than two thirds of the study period (Table 3). Annually measured SGRQ scores were improved in the $\mathrm{PH}$ group compared to the PL group, especially in terms of the symptoms and impact domains (Table 3). However, the presence of two or more moderate exacerbations per year, or of one or more severe exacerbations per year during the study period, did not differ among the groups. 
Persistently $<300$ cell per uL

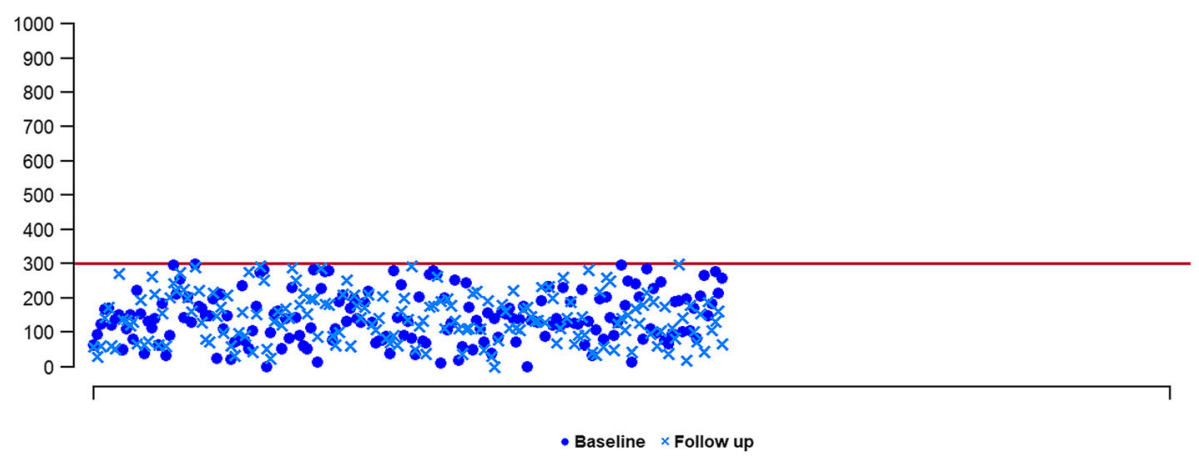

Variable

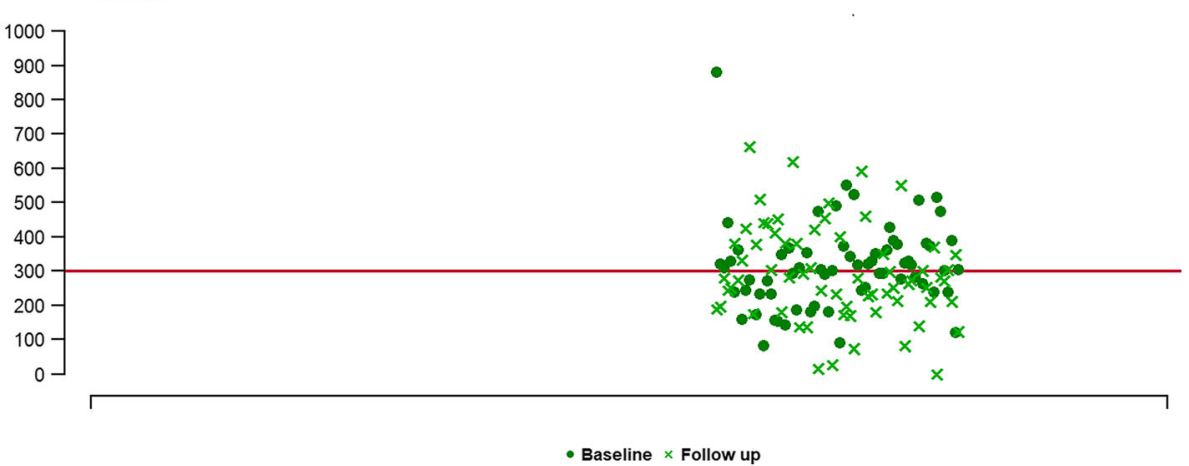

Persistently $\geq 300$ cell per uL

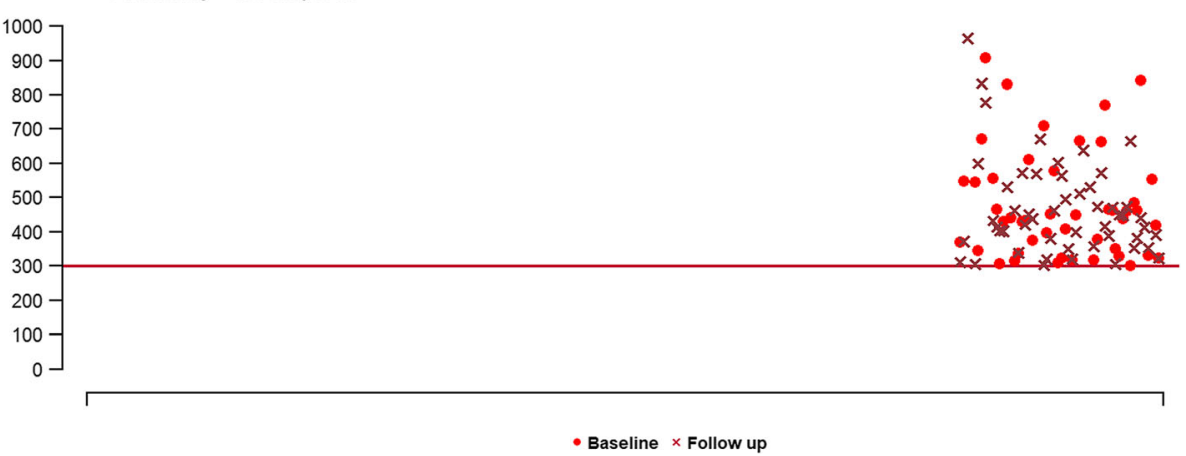

Fig. 1 Distribution of blood eosinophils across two serial measurements. Individual patients are shown along the horizontal axis. The top panel shows data for patients with blood eosinophils that were persistently below $300 \mathrm{cell} / \mathrm{s} / \mathrm{L}$. The middle panel shows data for patients with blood eosinophils that varied around 300 cells/ $\mu \mathrm{L}$. The bottom panel shows patients with blood eosinophils that were persistently equal to or greater than 300 cells/ $/ \mathrm{L}$. Nine and fourteen participants had counts above $1000 \mathrm{cells} / \mu \mathrm{L}$ in the variable and persistently high groups, respectively (not shown). ${ }^{*}$ The horizontal line at $300 \mathrm{cells} / \mu \mathrm{L}$ is defined as peripheral eosinophilia

\section{Discussion}

In this study, $77 \%$ of subjects had stable blood eosinophil count across two serial measurements when a cut-off of 300 cells $/ \mu \mathrm{L}$ was used. When patients were stratified into persistently low, variable, and persistently high blood eosinophil groups, no significant differences in baseline characteristics were detected among the groups. During a median follow-up period of 6 years, patients with persistently high blood eosinophils had a better survival rate and improved health-related quality of life measured by SGRQ score than those with persistently low blood eosinophils. However, no significant difference was found in annual lung function decline or exacerbations during the follow-up period among the groups.

The distribution of patients according to blood eosinophil stability in the current study does not agree with the results of the ECLIPSE study, in which only $13.6 \%$ of subjects had persistently low blood eosinophils, and $49 \%$ and $37.4 \%$ had variable and persistently high blood eosinophils, respectively [19]. Given that the stability of eosinophils decreases over 
Table 1 Baseline characteristics by eosinophil stability

\begin{tabular}{|c|c|c|c|c|}
\hline & Persistently $<300$ & Variable & Persistently $\geq 300$ & $P$-value \\
\hline Number & 175 & 68 & 56 & \\
\hline Age, years & $67.1(7.6)$ & $66.0(6.8)$ & $66.6(7.3)$ & 0.59 \\
\hline Sex & & & & 0.18 \\
\hline Female & $3(1.7)$ & $4(5.9)$ & $1(1.8)$ & \\
\hline Male & $172(98.3)$ & $64(94.1)$ & $55(98.2)$ & \\
\hline Smoking history & & & & 0.28 \\
\hline Current & $52(29.7)$ & $23(33.8)$ & $23(41.1)$ & \\
\hline Ex-smoker & $123(70.3)$ & $45(66.2)$ & $33(58.9)$ & \\
\hline $\mathrm{BMI}, \mathrm{kg} / \mathrm{m}^{2}$ & $22.8(3.5)$ & $23.5(2.7)$ & $23.9(3.0)$ & 0.07 \\
\hline Education & & & & 0.63 \\
\hline$<$ high school & $86(49.1)$ & $30(44.1)$ & $24(42.9)$ & \\
\hline$\geq$ high school & 89 (50.9) & $38(55.9)$ & $32(57.1)$ & \\
\hline $\mathrm{mMRC} \geq 2$ & $98(56.0)$ & $31(45.6)$ & $28(50.0)$ & 0.32 \\
\hline \multicolumn{5}{|l|}{ SGRQ } \\
\hline Symptoms & $44.1(19.0)$ & $41.1(18.8)$ & $46.3(16.9)$ & 0.39 \\
\hline Activity & $48.6(22.9)$ & $46.0(24.0)$ & $49.0(22.3)$ & 0.68 \\
\hline Impacts & $22.9(18.2)$ & $18.2(15.9)$ & $24.1(18.8)$ & 0.17 \\
\hline Total & 33.7 (17.5) & 30.7 (16.6) & $35.4(17.5)$ & 0.29 \\
\hline \multicolumn{5}{|l|}{ Acute exacerbation in the previous year ${ }^{a}$} \\
\hline$\geq 2$ Moderate AE & $15(8.6)$ & $1(1.5)$ & $6(10.7)$ & 0.09 \\
\hline$\geq 1$ Severe $A E$ & 19 (10.9) & $6(8.8)$ & $7(12.5)$ & 0.80 \\
\hline$\geq 2$ Moderate or $\geq 1$ severe $\mathrm{AE}$ & $30(17.1)$ & $7(10.3)$ & $12(21.4)$ & 0.23 \\
\hline Self-reported history of asthma & $52(29.7)$ & $17(25.0)$ & $15(26.8)$ & 0.74 \\
\hline \multicolumn{5}{|l|}{ Spirometry } \\
\hline $\mathrm{FEV}_{1}(\mathrm{~mL})$ & $1398.7(510.2)$ & $1538.1(531.0)$ & $1533.9(503.1)$ & 0.08 \\
\hline $\mathrm{FEV}_{1}, \%$ predicted & $46.5(15.7)$ & $50.7(14.8)$ & $49.8(14.2)$ & 0.10 \\
\hline $\mathrm{FVC}(\mathrm{mL})$ & $3234.1(784.1)$ & $3314.3(800.4)$ & $3240.2(775.5)$ & 0.77 \\
\hline FVC, \% predicted & $77.7(17.6)$ & $79.9(16.1)$ & $75.8(15.3)$ & 0.41 \\
\hline $\mathrm{FEV}_{1} / \mathrm{FVC}(\%)$ & $43.1(11.2)$ & $45.9(9.3)$ & $47.3(10.2)$ & 0.018 \\
\hline Post-bronchodilator $\mathrm{FEV}_{1}(\mathrm{~mL})$ & $1555.6(531.7)$ & $1690.7(537.9)$ & $1728.8(554.1)$ & 0.052 \\
\hline Post-bronchodilator $\mathrm{FEV}_{1}, \%$ predicted & $51.6(16.1)$ & $55.9(14.9)$ & $56.1(15.4)$ & 0.06 \\
\hline Post-bronchodilator $\mathrm{FEV}_{1}<50 \%$ predicted, $\mathrm{n}(\%)$ & $91(52.0)$ & $42(61.8)$ & $34(60.7)$ & 0.28 \\
\hline Positive reversibility, n (\%) & $54(30.9)$ & $21(30.9)$ & $19(33.9)$ & 0.91 \\
\hline Emphysema $>5 \%{ }^{\mathrm{b}}$ & $137(78.3)$ & $52(76.5)$ & $43(76.8)$ & 0.94 \\
\hline \multicolumn{5}{|l|}{ Inhaler use } \\
\hline LAMA & $75(42.9)$ & $22(32.4)$ & $14(25.0)$ & 0.036 \\
\hline ICS/LABA or ICS & $71(40.6)$ & $22(32.4)$ & $28(50.0)$ & 0.14 \\
\hline Blood Eosinophils & $143.4(73.4)$ & $339.0(191.6)$ & $681.0(595.6)$ & $<0.001$ \\
\hline Interval between two Eosinophil count, months & $12.2(4.5)$ & $12.1(4.0)$ & $12.9(6.4)$ & 0.56 \\
\hline
\end{tabular}

The data are presented as number (\%) or as mean (SD)

Abbreviations: $B M I$ body mass index, $m M R C$ modified Medical Research Council, SGRQ St George's Respiratory Questionnaire, $A E$ acute exacerbation, $F E V_{1}$ forced expiratory volume in 1 second, FVC forced vital capacity, LAMA long acting muscarinic antagonist, ICS inhaled corticosteroids, LABA long acting beta2-agonist, SD standard deviation

${ }^{a}$ Moderate AE was defined as a clinic visit and severe AE was defined as a hospitalization or an emergency room visit owing to one or more of the following: worsening of dyspnea, increased sputum volume and purulent sputum

${ }^{b}$ Emphysema was defined as a percentage of lung attenuation less than 950 Hounsfield units. Percent emphysema was determined for total lung 
Table 2 Association between eosinophil stability and all-cause mortality

\begin{tabular}{|c|c|c|c|c|c|}
\hline & Person-years & No. of cases & $\begin{array}{l}\text { Mortality rate } \\
\text { (per } 100 \text { person-years) }\end{array}$ & $\begin{array}{l}\text { Crude MRR } \\
(95 \% \mathrm{Cl})\end{array}$ & $\begin{array}{l}\text { Adjusted* MRR } \\
(95 \% \mathrm{Cl})\end{array}$ \\
\hline $\begin{array}{l}\text { Persistently }<300 \\
(n=175)\end{array}$ & 935.2 & 28 & 3.0 & Reference & Reference \\
\hline $\begin{array}{l}\text { Variable } \\
(\mathrm{n}=68)\end{array}$ & 386.4 & 5 & 1.3 & $0.68(0.32,1.43)$ & $0.78(0.37,1.66)$ \\
\hline $\begin{array}{l}\text { Persistently } \geq 300 \\
(n=56)\end{array}$ & 327.6 & 2 & 0.6 & $0.27(0.08,0.87)$ & $0.29(0.09,0.97)$ \\
\hline
\end{tabular}

$(\mathrm{n}=56)$

Abbreviations: $\mathrm{Cl}$ confidence interval, $M R R$ mortality rate ratio

*Adjusted for age, smoking status, self-reported history of asthma, two or more moderate exacerbations or one or more severe exacerbation during the previous year, post-bronchodilator $\mathrm{FEV}_{1}<50 \%$ predicted at baseline, and use of inhaled corticosteroids (ICS)/long-acting $\beta_{2}$-agonist or ICS for more than two thirds of the study period

time, [25] the use of only two serial measurements (mostly baseline and at 1 year) in the current study would explain the difference between the stability of blood eosinophils reported here and those measured in the ECLIPSE study (where measurements were taken over a 3-year follow-up period). Although the number of subjects significantly decreased as the number of measurements increased in the current study, $47.0 \%$ of subject showed persistently low blood eosinophils, and $41.2 \%$ and $11.8 \%$ had variable and persistently high blood eosinophils among the 170 patients who underwent four measurements of blood eosinophils during follow-up (Additional file 1: Table S2). This proportion was consistent with those from BMI, Obstruction, Dyspnea, Exercise (BODE) index cohort and COPD History Assessment in Spain (CHAIN) cohort, which used a cut-off of 300 cells $/ \mu \mathrm{L}$ and three serial measurements [22]. Thus, the difference in blood eosinophils stability most likely arises from the ECLIPSE cut-off value of $2 \%$, which is surpassed in $57-75 \%$ of COPD patients [11, 33]. Such a low threshold for eosinophils might have diluted the differences within eosinophilic inflammation, similar to the way in which the benefit of ICS for exacerbation prevention becomes more obvious as the eosinophil threshold rises [8-10, 34]. In addition, the relative percentage using the total leukocyte count is thought to be less reliable than the absolute blood eosinophil count [35]. Thus, a higher threshold of 300 cells $/ \mu \mathrm{L}$ was used in this study for the absolute eosinophil count based on previous studies [10, 20, 27] and expert consensus on the asthma-COPD overlap [36].

Using an absolute eosinophil count of 300 cells/ $\mu \mathrm{L}$ from two serial measurements as the cut-off, the current study found that patients with persistently high blood eosinophils had a better survival rate than those with persistently low blood eosinophils. These results are consistent with those of recent studies that used at least three measurements of blood eosinophils [22, 23]. In a study using data from the BODE cohort, patients with blood eosinophils persistently lower than 300 cells $/ \mu \mathrm{L}$ over 2 years (three measurements) had an increased risk of all-cause mortality [adjusted hazard ratio, 7.287 (95\% CI, 1.004-52.891); $p=0.050$ ] [22]. Another study revealed that patients with blood eosinophils

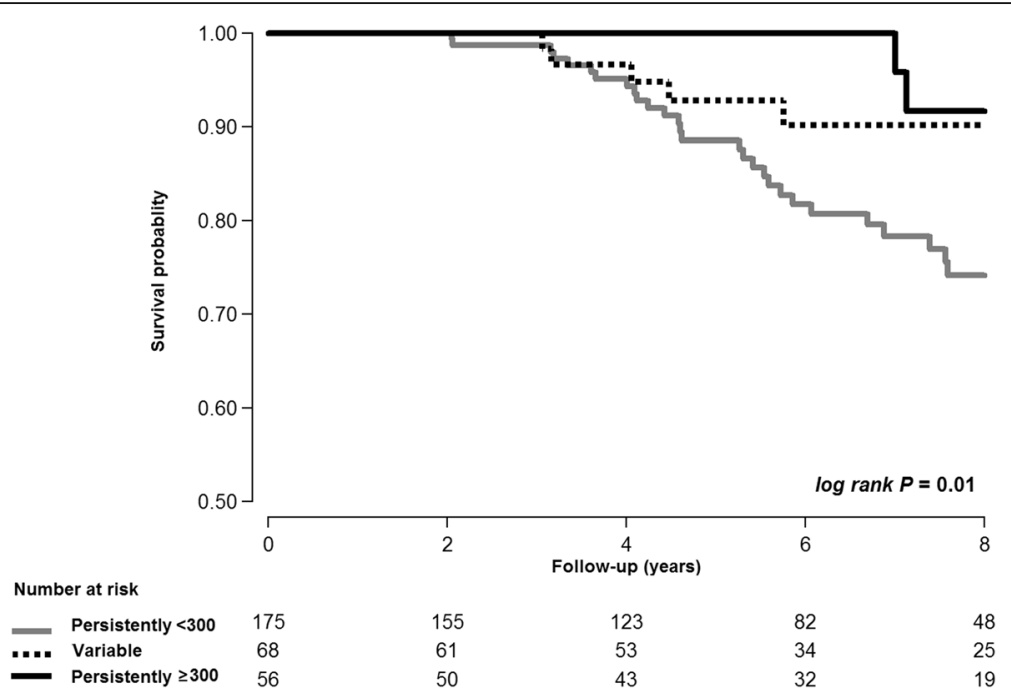

Fig. 2 Kaplan-Meier curves for mortality according to blood eosinophil stability 
Table 3 Change of lung function and SGRQ score over time by eosinophil stability

\begin{tabular}{|c|c|c|c|}
\hline & $\begin{array}{l}\text { Persistently }<300 \\
(n=175)\end{array}$ & $\begin{array}{l}\text { Variable } \\
(n=68)\end{array}$ & $\begin{array}{l}\text { Persistently } \geq 300 \\
(n=56)\end{array}$ \\
\hline \multicolumn{4}{|l|}{$\mathrm{FEV}_{1}, \mathrm{~mL}$} \\
\hline Change of $\mathrm{FEV}_{1}, \mathrm{~mL} /$ year & $-29.71(-37.90,-21.52)$ & $-18.48(-31.03,-5.92)$ & $-28.15(-41.61,-14.69)$ \\
\hline Difference in change of $\mathrm{FEV}_{1}, \mathrm{~mL} /$ year & Reference & $11.23(-3.76,26.23)$ & $1.56(-14.20,17.32)$ \\
\hline Adjusted $^{a}$ change of $\mathrm{FEV}_{1}$, $\mathrm{mL} /$ year & $-29.66(-37.92,-21.41)$ & $-18.42(-31.06,-5.79)$ & $-28.15(-41.70,-14.60)$ \\
\hline Adjusted $^{a}$ difference in change of $\mathrm{FEV}_{1}, \mathrm{~mL} /$ year & Reference & $11.23(-3.86,26.32)$ & $1.50(-14.36,17.36)$ \\
\hline \multicolumn{4}{|l|}{ SGRQ score } \\
\hline \multicolumn{4}{|l|}{ Symptoms } \\
\hline Adjusted $^{b}$ change of score /year & $-0.22(-1.45,1.01)$ & $1.45(-0.34,3.24)$ & $-2.75(-4.77,-0.73)$ \\
\hline Adjusted $^{\mathrm{b}}$ difference in score /year & Reference & $1.68(-0.50,3.85)$ & $-2.53(-4.89,-0.16)$ \\
\hline \multicolumn{4}{|l|}{ Activity } \\
\hline Adjusted $^{\mathrm{b}}$ change of score /year & $0.14(-1.61,1.88)$ & $0.23(-2.36,2.81)$ & $-1.07(-3.91,1.77)$ \\
\hline Adjusted $^{b}$ difference in score /year & Reference & $0.09(-3.03,3.21)$ & $-1.21(-4.54,2.13)$ \\
\hline \multicolumn{4}{|l|}{ Impact } \\
\hline Adjusted $^{\mathrm{b}}$ change of score /year & $0.73(-0.62,2.07)$ & $-0.24(-2.22,1.75)$ & $-2.44(-4.63,-0.25)$ \\
\hline Adjusted $^{b}$ difference in score /year & Reference & $-0.97(-3.36,1.43)$ & $-3.17(-5.74,-0.60)$ \\
\hline \multicolumn{4}{|l|}{ Total } \\
\hline Adjusted $^{\mathrm{b}}$ change of score /year & $0.26(-1.15,1.66)$ & $0.14(-1.95,2.24)$ & $-2.34(-4.63,-0.04)$ \\
\hline Adjusted $^{b}$ difference in score /year & Reference & $-0.11(-2.64,2.41)$ & $-2.59(-5.29,0.09)$ \\
\hline
\end{tabular}

Abbreviations: SGRQ St George's Respiratory Questionnaire, FEV forced expiratory volume in 1 second

${ }^{a}$ Adjusted for age, smoking status, self-reported history of asthma, two or more moderate exacerbations or one or more severe exacerbation during the previous year, and use of inhaled corticosteroids(ICS)/long-acting $\beta_{2}$-agonist or ICS for more than two thirds of the study period

${ }^{b}$ Adjusted for age, smoking status, self-reported history of asthma, two or more moderate exacerbations or one or more severe exacerbation during the previous year, post-bronchodilator $\mathrm{FEV}_{1}<50 \%$ predicted at baseline, and use of inhaled corticosteroids (ICS)/long-acting $\beta_{2}$-agonist or ICS for more than two thirds of the study period

persistently $\geq 150$ cell $/ \mu \mathrm{L}$ over 5 years had a better survival rate than other patients $(p<0.01)$ [23]. A study using only one eosinophil measurement in patients with severe exacerbation found that eosinopenia $(<50$ cell $/ \mu \mathrm{L})$ was associated with increased in-hospital mortality [odds ratio, 2.76 (95\% CI, 1.58-4.83), $p=0.001$ ] [37]. Data from the Hokkaido COPD cohort showed that COPD patients with two or more asthma-like features (including a baseline blood eosinophil count $\geq 300$ cells $/ \mu \mathrm{L}$ ) had significantly lower 10 -year all-cause mortality $(p=0.020)$ than other patients, but baseline eosinophilia alone did not reach statistical significance for all-cause mortality [20]. Given that the V group in the current study did not differ significantly from the PL group in terms of mortality, but the PH group had significantly lower mortality, at least two eosinophil counts appear to be necessary to identify patients with different clinical courses.

This study also found that patients with persistently high blood eosinophils had an improved SGRQ score, especially in terms of the symptoms and impact domains of the SGRQ, than those with persistently low blood eosinophils. However, although there was a trend toward a reduced rate of $\mathrm{FEV}_{1}$ decline in the $\mathrm{V}$ group, those groups with persistently low, variable, and persistently high blood eosinophils showed no difference in annual lung function decline. This finding is consistent with that of the ECLIPSE investigators, who found no significant differences in the rate of decline in $\mathrm{FEV}_{1}$ according to blood eosinophil pattern using a cut-off value of $2 \%$. In a re-analysis of the Inhaled Steroids in Obstructive Lung Disease (ISOLDE) trial, ICS treatment led to a reduced rate of $\mathrm{FEV}_{1}$ decline in COPD patients with a baseline blood eosinophil count of $\geq 2 \%$ compared to those with a baseline blood eosinophil count of $<2 \%$ [7]. In the current study, the proportion of users of ICS treatment was similar between the groups (Additional file 1: Table S1), which might contribute to a lack of signals for annual lung function decline.

The present study had several limitations. First, this study defined COPD using a fixed airflow limitation with a smoking history of more than 10 pack-years and 97\% of the subjects were male, which could limit the generalisability to non-smoking and/or female patients. In Korea, the prevalence of COPD is four times lower in females compared to males and this gender discrepancy is largely due to the very low smoking rate among females $[38,39]$. Second, the results of this study should be interpreted in light of its retrospective nature and prospectively collected data, as well as the relatively small sample size, despite the long median follow-up duration. 
Third, an optimal interval between blood eosinophil measurements necessary to establish a patient's blood eosinophil count as persistently high was unable to be determined. Further studies are necessary to determine whether those with persistently high eosinophils during short-term follow-up (i.e., 6 months) have consistent results. Finally, since blood eosinophils were unable to be compared to those of sputum eosinophils or other inflammatory markers (e.g., IL-5, IL-13) in the study subjects, there was limited evidence to support the biologic plausibility of these findings.

In conclusion, COPD patients with persistently high blood eosinophils had a better survival rate and improved symptoms and impact domains of SGRQ score than those with persistently low blood eosinophils, while those with variable blood eosinophils had survival rates similar to those with persistently low blood eosinophils. Two serial measurements of blood eosinophils could therefore help predict the outcomes of COPD patients, but this finding should be validated in a future study with a larger number of subjects.

\section{Additional file}

Additional file 1: Table S1. Use of ICS containing inhalers or systemic corticosteroids during the follow-up period. Table S2. Stability of blood eosinophils in patients with blood eosinophils measured more than two times. (DOCX $21 \mathrm{~kb})$

\section{Abbreviation}

COPD: chronic obstructive lung disease; $\mathrm{FEV}_{1}$ : forced expiratory volume in 1 second; FVC: forced vital capacity; ICS: inhaled corticosteroids; KOLD: Korean Obstructive Lung Disease; LABA: long-acting $\beta_{2}$-agonist; MRR: mortality rate ratio; $\mathrm{PH}$ : persistently high; $\mathrm{PL}$ : persistently low; V: variable

\section{Funding}

The KOLD Study was supported by a grant from the Korean Health 21 R\&D Project, Ministry of Health and Welfare, Republic of Korea (H110C2020 and A102065). This study was supported by the Samsung Medical Center Foundation for Medical Research (SMX1151371).

\section{Availability of data and materials}

The datasets used and/or analysed during the current study are available from the corresponding author on reasonable request

\section{Authors' contributions}

Conception and design of the study: SHS, HYP, and WJK; Data generation: HYP, SOK, JHP, JSL, Y-MO, and S-DL; Analysis and interpretation of the data: SHS, HYP, DK, JC; Preparation or critical revision of the manuscript: SHS, HYP, DK, JC, SOK, JHP, JSL, Y-MO, DDS, WJK, and S-DL. All authors read and approved the final manuscript.

\section{Ethics approval and consent to participate}

The study protocol was approved by the Institutional Review Board of Asan Medical Center (no. 2005-0010). Written informed consent was obtained from all participants.

\section{Consent for publication}

Not applicable.

\section{Competing interests}

H.Y.P. has received lecture fees from AstraZeneca, Novartis, and BoehringerIngelheim.
D.D.S. is funded by the Canada Research Chair Program and has received honoraria for speaking engagements from Boehringer-Ingelheim, AstraZeneca, Regeneron, and Sanofi Aventis over the past 18 months. He has also received research funding from $B I, A Z$ and Merck during this time. None declared (S.H.S., D.K., J.C., S.O.K., J.H.P., J.S.L., Y-M.O., W.J.K., and S-D.L.).

\section{Publisher's Note}

Springer Nature remains neutral with regard to jurisdictional claims in published maps and institutional affiliations.

\section{Author details}

'Division of Pulmonary and Critical Care Medicine, Department of Medicine, Samsung Medical Center, Sungkyunkwan University School of Medicine, 81 Irwon-ro, Gangnam-gu, Seoul 06351, South Korea. ${ }^{2}$ Departments of Health Sciences and Technology and Clinical Research Design and Evaluation, Samsung Advanced Institute of Health Sciences and Technology, Sungkyunkwan University, Seoul, South Korea. ${ }^{3}$ Cancer Education Center, Samsung Comprehensive Cancer Center, Samsung Medical Center, Sungkyunkwan University School of Medicine, Seoul, South Korea. ${ }^{4}$ Departments of Health, Behavior, and Society and Epidemiology, Johns Hopkins Bloomberg School of Public Health, Baltimore, MD, USA. ${ }^{5}$ Biomedical Research Institute, Kangwon National University Hospital, Chuncheon, South Korea. ${ }^{6}$ Department of Pulmonary and Critical Care Medicine, Ajou University School of Medicine, Suwon, South Korea. ${ }^{7}$ Department of Pulmonary and Critical Care Medicine, Clinical Research Center for Chronic Obstructive Airway Diseases, Asan Medical Center, University of Ulsan College of Medicine, Seoul, South Korea. ${ }^{8}$ Respiratory Division, Department of Medicine, University of British Columbia, Vancouver, BC, Canada. ${ }^{9}$ Department of Internal Medicine and Environmental Health Center, Kangwon National University Hospital, School of Medicine, Kangwon National University, 156 Baengyeong-ro, Chuncheon-si, Gangwon-do 200-722, South Korea.

Received: 7 February 2018 Accepted: 5 July 2018

Published online: 13 July 2018

\section{References}

1. O'Donnell RA, Peebles C, Ward JA, Daraker A, Angco G, Broberg P, et al. Relationship between peripheral airway dysfunction, airway obstruction, and neutrophilic inflammation in COPD. Thorax. 2004;59:837-42.

2. Pizzichini E, Pizzichini MM, Gibson P, Parameswaran K, Gleich GJ, Berman L, et al. Sputum eosinophilia predicts benefit from prednisone in smokers with chronic obstructive bronchitis. Am J Respir Crit Care Med. 1998;158:1511-7.

3. Brightling CE, McKenna S, Hargadon B, Birring S, Green R, Siva R, et al. Sputum eosinophilia and the short term response to inhaled mometasone in chronic obstructive pulmonary disease. Thorax. 2005;60:193-8.

4. Bafadhel M, McKenna S, Terry S, Mistry V, Reid C, Haldar P, et al. Acute exacerbations of chronic obstructive pulmonary disease: identification of biologic clusters and their biomarkers. Am J Respir Crit Care Med. 2011;184: 662-71.

5. Bafadhel M, McKenna S, Terry S, Mistry V, Pancholi M, Venge P, et al. Blood eosinophils to direct corticosteroid treatment of exacerbations of chronic obstructive pulmonary disease: a randomized placebo-controlled trial. Am J Respir Crit Care Med. 2012;186:48-55.

6. Negewo NA, McDonald VM, Baines KJ, Wark PAB, Simpson JL, Jones PW, et al. Peripheral blood eosinophils: a surrogate marker for airway eosinophilia in stable COPD. International Journal of Chronic Obstructive Pulmonary Disease. 2016;11:1495-504.

7. Barnes NC, Sharma R, Lettis S, Calverley PM. Blood eosinophils as a marker of response to inhaled corticosteroids in COPD. Eur Respir J. 2016;47:1374-82.

8. Siddiqui $\mathrm{SH}$, Guasconi A, Vestbo J, Jones P, Agusti A, Paggiaro P, et al. Blood eosinophils: a biomarker of response to extrafine beclomethasone/ formoterol in chronic obstructive pulmonary disease. Am J Respir Crit Care Med. 2015;192:523-5.

9. Pascoe S, Locantore N, Dransfield MT, Barnes NC, Pavord ID. Blood eosinophil counts, exacerbations, and response to the addition of inhaled fluticasone furoate to vilanterol in patients with chronic obstructive pulmonary disease: a secondary analysis of data from two parallel randomised controlled trials. Lancet Respir Med. 2015;3:435-42.

10. Watz $\mathrm{H}$, Tetzlaff $\mathrm{K}$, Wouters EF, Kirsten A, Magnussen $\mathrm{H}$, Rodriguez-Roisin $\mathrm{R}$, et al. Blood eosinophil count and exacerbations in severe chronic 
obstructive pulmonary disease after withdrawal of inhaled corticosteroids: a post-hoc analysis of the WISDOM trial. Lancet Respir Med. 2016:4:390-8.

11. Pavord ID, Lettis S, Locantore N, Pascoe S, Jones PW, Wedzicha JA, et al. Blood eosinophils and inhaled corticosteroid/long-acting beta-2 agonist efficacy in COPD. Thorax. 2016;71:118-25.

12. Bafadhel M, Peterson S, De Blas MA, Calverley PM, Rennard SI, Richter K, et al. Predictors of exacerbation risk and response to budesonide in patients with chronic obstructive pulmonary disease: a post-hoc analysis of three randomised trials. Lancet Respir Med. 2018;6:117-26.

13. Suissa S, Coulombe J, Ernst P. Discontinuation of inhaled corticosteroids in COPD and the risk reduction of pneumonia. Chest. 2015;148:1177-83.

14. Magnussen $H$, Disse B, Rodriguez-Roisin R, Kirsten A, Watz $H$, Tetzlaff $K$, et al. Withdrawal of inhaled glucocorticoids and exacerbations of COPD. N Engl J Med. 2014;371:1285-94.

15. Wedzicha JA, Banerji D, Chapman KR, Vestbo J, Roche N, Ayers RT, et al. Indacaterol-glycopyrronium versus salmeterol-fluticasone for COPD. N Engl J Med. 2016:374:2222-34

16. Global Initiative for Chronic Obstructive Lung Disease (GOLD). Global strategy for the diagnosis, management, and prevention of chronic obstructive pulmonary disease 2018 report. 2018. Available from http:// www.goldcopd.org/.

17. Vedel-Krogh S, Nielsen SF, Lange P, Vestbo J, Nordestgaard BG. Blood eosinophils and exacerbations in chronic obstructive pulmonary disease. The Copenhagen general population study. Am J Respir Crit Care Med. 2016;193:965-74.

18. Couillard S, Larivee P, Courteau J, Vanasse A. Eosinophils in COPD exacerbations are associated with increased readmissions. Chest. 2017;151: 366-73.

19. Singh $D$, Kolsum U, Brightling CE, Locantore $N$, Agusti A, Tal-Singer R. Eosinophilic inflammation in COPD: prevalence and clinical characteristics. Eur Respir J. 2014;44:1697-700.

20. Suzuki M, Makita H, Konno S, Shimizu K, Kimura H, Kimura H, et al. Asthmalike features and clinical course of chronic obstructive pulmonary disease. An analysis from the Hokkaido COPD cohort study. Am J Respir Crit Care Med. 2016;194:1358-65.

21. DiSantostefano RL, Hinds D, Le HV, Barnes NC. Relationship between blood eosinophils and clinical characteristics in a cross-sectional study of a US population-based COPD cohort. Respir Med. 2016;112:88-96.

22. Casanova C, Celli BR, de-Torres JP, Martinez-Gonzalez C, Cosio BG. Prevalence of persistent blood eosinophilia: relation to outcomes in patients with COPD. Eur Respir J. 2017;50

23. Turato G, Semenzato U, Bazzan E, Biondini D, Tine M, Torrecilla N, et al. Blood eosinophilia does not reflect tissue eosinophils nor worsen clinical outcomes in COPD. Am J Respir Crit Care Med. 2017;

24. Bafadhel M, Pavord ID, Russell REK. Eosinophils in COPD: just another biomarker? Lancet Respir Med. 2017;5:747-59.

25. Oshagbemi OA, Burden AM, Braeken DCW, Henskens Y, Wouters EFM Driessen JHM, et al. Stability of blood eosinophils in patients with chronic obstructive pulmonary disease and in control subjects, and the impact of sex, age, smoking, and baseline counts. Am J Respir Crit Care Med. 2017; 195:1402-4.

26. Park TS, Lee JS, Seo JB, Hong Y, Yoo JW, Kang BJ, et al. Study design and outcomes of Korean obstructive lung disease (KOLD) cohort study. Tuberc Respir Dis (Seoul). 2014;76:169-74.

27. Chapman KR, Hurst JR, Frent SM, Larbig M, Fogel R, Guerin T, et al. Longterm triple therapy de-escalation to indacaterol/glycopyrronium in COPD patients (SUNSET): a randomized, double-blind, triple-dummy clinical trial. Am J Respir Crit Care Med. 2018;

28. Miller MR, Hankinson J, Brusasco V, Burgos F, Casaburi R, Coates A, et al. Standardisation of spirometry. Eur Respir J. 2005;26:319-38.

29. Choi J, K., Paek D, Lee JO. Normal predictive values of spirometry in Korean population. Tuberc Respir Dis 2005;58:230-242

30. Jones PW, Quirk FH, Baveystock CM. The St George's respiratory questionnaire. Respir Med 1991;85 Suppl B:25-31; discussion 3-7.

31. Lee JS, Rhee CK, Yoo KH, Lee JH, Yoon HI, Kim TH, et al. Three-month treatment response and exacerbation in chronic obstructive pulmonary disease. J Korean Med Sci. 2015;30:54-9.

32. Fitzmaurice GM, Laird NM, Ware JH. Applied longitudinal analysis. 2nd ed. Hoboken, NJ: Wiley; 2011

33. Roche N, Chapman KR, Vogelmeier CF, Herth FJF, Thach C, Fogel R, et al. Blood eosinophils and response to maintenance chronic obstructive pulmonary disease treatment. Data from the FLAME trial. Am J Respir Crit Care Med. 2017:195:1189-97.

34. Calverley PM, Tetzlaff K, Vogelmeier C, Fabbri LM, Magnussen H, Wouters EF, et al. Eosinophilia, frequent exacerbations, and steroid response in chronic obstructive pulmonary disease. Am J Respir Crit Care Med. 2017;

35. Wedzicha JA. Eosinophils as biomarkers of chronic obstructive pulmonary disease exacerbation risk. Maybe just for some? Am J Respir Crit Care Med. 2016;193:937-8.

36. Sin DD, Miravitlles M, Mannino DM, Soriano JB, Price D, Celli BR, et al. What is asthma-COPD overlap syndrome? Towards a consensus definition from a round table discussion. Eur Respir J. 2016:48:664-73.

37. Steer J, Gibson J, Bourke SC. The DECAF score: predicting hospital mortality in exacerbations of chronic obstructive pulmonary disease. Thorax. 2012;67: 970-6.

38. Yoo KH. Smoking cessation and chronic obstructive pulmonary disease. Korean J Intern Med. 2015:30:163-6.

39. Hwang YI, Park YB, Yoo KH. Recent trends in the prevalence of chronic obstructive pulmonary disease in Korea. Tuberc Respir Dis (Seoul). 2017;80: 226-9.

Ready to submit your research? Choose BMC and benefit from

- fast, convenient online submission

- thorough peer review by experienced researchers in your field

- rapid publication on acceptance

- support for research data, including large and complex data types

- gold Open Access which fosters wider collaboration and increased citations

- maximum visibility for your research: over $100 \mathrm{M}$ website views per year

At BMC, research is always in progress.

Learn more biomedcentral.com/submissions 